\title{
RNA and lessons from viruses
}

\author{
MARIE-LOUISE HAMMARSKJÖLD \\ Myles H. Thaler Center for AIDS and Human Retrovirus Research, Department of Microbiology, University of Virginia, Charlottesville, Virginia \\ 22908, USA
}

I still remember my excitement when the RNA Society was started, especially when I found out that a new journal "RNA" was in the works. I was thrilled to find out that the Editor-in-Chief was going to be the outstanding basic RNA biologist, Tim Nilsen. After 20 years Tim and RNA are still going strong, in itself a remarkable achievement! Also, the past 20 years have been full of often unexpected and truly exciting new discoveries and accomplishments in RNA biology. We will never know exactly how much having the RNA Society and "our" journal have contributed to these successes. However, I know for a fact that they have played major roles in my own scientific thinking and work.

What have been the most significant advances in the field since the inception of the journal? While there have obviously been many, I have decided to focus my reflections on what still excites me the most: the tremendous advances that have been made in the area of post-transcriptional RNA regulation. For many young RNA biologists out there, 20 years may seem like a very long time. However, from my perspective, the years since $R N A$ was started have gone by very fast and are only the rather recent past of almost 50 years of personal interest in RNA and its many functions.

When I was a starting student in the late 1960's, the importance of RNA as "messengers" of DNA information in the cytoplasm had just been elucidated. One of the first things that left me astonished and puzzled was the discovery of "heterogenous nuclear RNA (hnRNA)" by the Darnell group. It seemed to make absolutely no sense that much of the "prospective mRNA" never reached the cytoplasm. At the time, I was just starting my research on Adenovirus (regrettably a DNA virus, not an RNA one!). The explanation for the existence of hnRNA didn't come until 1977, when "splicing" was discovered in Adenovirus-infected human cells by groups at CSHL (Chow, Broker, and Roberts) and MIT (Berget and Sharp). I remember vivid discussions, debating whether this was just a specific viral mechanism or something used by the host cell as well. Of course that debate was quickly settled by the discovery of splicing in ovalbumin (Chambon group), globin (Leder group), and other genes.

Corresponding author: mh7g@virginia.edu

Article and publication date are at http://www.rnajournal.org/cgi/doi/ 10.1261/rna.050310.115. Freely available online through the RNA Open Access option.
Fast forward to 1995, when the RNA Society was established and the new journal was started. At that time, I had already seen the light and realized that RNA was much more interesting than DNA. I had switched to working on HIV, which is now by far the most widely studied RNA virus in the world. Early work in the late 1980's by the Haseltine and Wong-Staal groups made it clear that HIV used splicing in unusual ways (blurring the distinction between introns and exons). By the early 1990's, it had been shown that HIV RNA is alternatively spliced in a very complicated and, to me, still amazing fashion, making over 40 potential different mRNAs from one primary transcript. A very curious finding was that many of these mRNAs retained introns.

At that time, the general dogma was that introns were quickly removed from pre-mRNA and if they were not, that the mRNA was retained in the nucleus and degraded. David Rekosh and I were lucky enough to stumble upon the mechanism that HIV uses to overcome this nuclear retention, starting our now 30-year husband-wife collaboration in the wonderful world of RNA. In independent work from several groups (Felber/Pavlakis, Cullen, Emerman) in addition to our own, HIV was shown to use a viral protein (Rev) that binds to a cis-acting element (RRE) in all of the mRNAs that retain introns. This enables these mRNAs to get efficiently exported from the nucleus to the cytoplasm, where they are translated into proteins (thus escaping Nonsense Mediated Decay [NMD] as well). This work directly led to our long-standing interest in alternative splicing, especially intron retention.

By 1995, alternative splicing was generally appreciated as an important gene regulation mechanism in eukaryotic cells, but we certainly did not appreciate the magnitude of regulation at this level. Twenty years later, we now know that almost all of the genes in higher eukaryotes are spliced in multiple alternative ways (many of them beating HIV hands down). This, coupled with other mechanisms (alternative promoters, alternative polyA sites, etc.), leads to protein diversity far beyond the number of genes. In combination with the discovery of miRNAs/siRNAs and the many novel species of non-coding RNAs, it also points us to exquisite mechanisms for post-

(C) 2015 Hammarskjöld This article, published in RNA, is available under a Creative Commons License (Attribution-NonCommercial 4.0 International), as described at http://creativecommons.org/licenses/by-nc/4.0/. 
transcriptional regulation that we still know relatively little about.

Post-transcriptional gene regulation seems to be of special importance in the brain, where many unique mRNAs and non-coding RNAs have been identified. Trafficking of RNA in dendrites and axons of neuronal cells have been studied for many years, but how signals from other cells regulate alternative splicing or how nucleo-cytoplasmic mRNA export relates to cytoplasmic trafficking and translation are just a few of the things that remain to be elucidated.

My interest in this area stems from our discovery that many simpler retroviruses use cis-acting RNA elements functionally similar to the HIV RRE to achieve export and expression of their mRNAs with retained introns. We named these Constitutive Transport Elements (CTEs), since they function directly with host cell proteins, not requiring expression of any viral proteins. The first CTE was discovered in MasonPfizer Monkey Virus (MPMV) and our first article in RNA (published in 1997) described the secondary structure of the MPMV CTE and identified essential nucleotides in this element. We were very happy to be able to publish our findings in a journal where we knew they would reach a wide RNA "audience." Subsequently, the Izzauralde and Felber groups used the CTE to identify the host cell protein that binds specifically to this element. The binding protein turned out to be Nxf1 (then known as Tap), now of course recognized as an important mRNA export receptor in most eukaryotic cells. In conjunction with the co-factor Nxt1 (p15), Nxf1 binds to the CTE and this can be used to replace the requirement for Rev/RRE in HIV expression and replication.

For several years, the MPMV CTE was thought of as a viral "invention," simply enabling the hijacking of Nxf1/Nxt1 for purposes other than their "normal" function in the host cell. However, in 2006 our group demonstrated that the NXF1 gene itself contains an element in one of the introns with striking primary homology to the MPMV CTE. This "cellu- lar" CTE enables export and expression of an alternative NXF1 mRNA that retains the CTE-containing intron. In a new 2015 publication in RNA (still the obvious choice!), we have now demonstrated that the CTE in the NXF1 gene is evolutionary conserved in multiple mammalian and nonmammalian species, including teleost fish. We have also shown that zebrafish Nxf1 and Nxt1 proteins can be expressed in human cells to enable efficient expression of HIV mRNAs with retained introns, when these mRNAs contain a zebrafish CTE. This demonstrates that species from zebrafish to man contain a molecular machinery for export and expression of mRNAs with retained introns. Although targets other than the NXF1 gene itself remain to be identified, this work identifies a clear mechanism for export and expression of such mRNAs that bypasses both nuclear retention and NMD. We have unpublished data to show that the alternative Nxf1 protein is highly expressed in cortical and hippocampal neurons in the rodent brain and that it co-localizes with Staufen and other neuronal "granule" proteins in dendrites.

Intron retention was previously thought to be rare in mammalian cells (although it is common in plants). However, technical advances such as "RNA-seq" have now allowed a more unbiased look at intron retention. Several recent articles suggest that intron retention is much more common than expected (deSouza, Blencowe, Sharp, Eberwine, and other groups). The Eberwine group recently hypothesized that intron retention plays an important role in neuronal gene regulation. While the ultimate fates of these mRNAs are still unclear, it highlights how much we yet have to learn about alternative splicing and how this and other post-transcriptional mechanisms are used in complicated gene regulation circuits. How the brain functions at the molecular level, and how RNA biology relates to "synaptic plasticity" and other brain functions and ultimately to human "consciousness," is still largely a "black box." In my mind, trying to unravel this will be one of the great challenges for the next 20 years! 

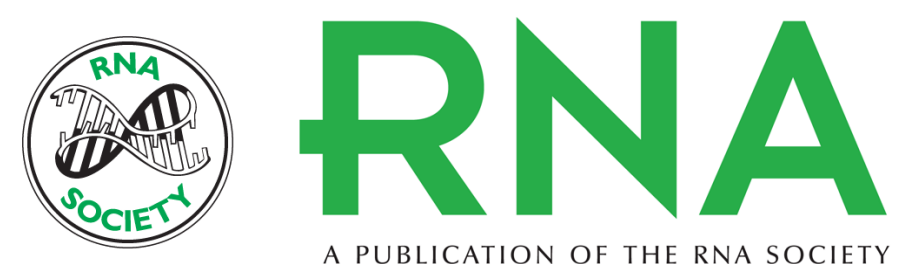

A PUBLICATION OF THE RNA SOCIETY

\section{RNA and lessons from viruses}

Marie-Louise Hammarskjöld

RNA 2015 21: 632-633

Open Access Freely available online through the RNA Open Access option.

Creative This article, published in RNA, is available under a Creative Commons License Commons (Attribution-NonCommercial 4.0 International), as described at License http://creativecommons.org/licenses/by-nc/4.0/.

Email Alerting Receive free email alerts when new articles cite this article - sign up in the box at the Service top right corner of the article or click here.

To subscribe to $R N A$ go to:

http://rnajournal.cshlp.org/subscriptions 